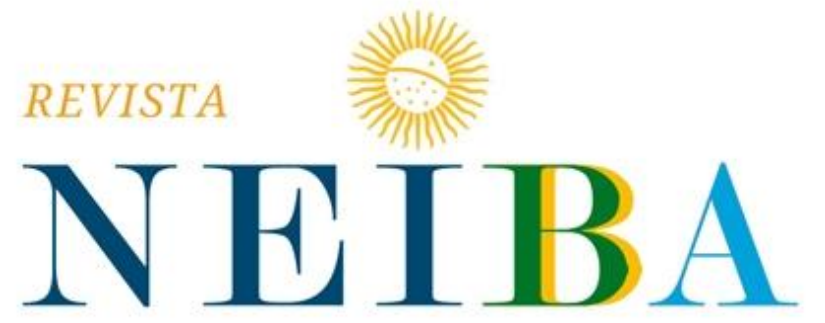

CADERNOS ARGENTINA-BRASIL

Volume 9, 2020, p. 01-24

DOI: 10.12957/neiba.2020.50569 | e50569 I ISSN: 2317-3459

\title{
GREVES POLICIAIS, SAQUES E ALGUNS LIMITES DA ORDEM SOCIAL EM CÓRDOBA E RECIFE
}

HUELGAS POLICIALES, SAQUEOS Y ALGUNOS LÍMITES DE LA ORDEN SOCIAL EN CÓRDOBA Y RECIFE

\section{Pedro de Barros Correia Amaral ${ }^{1}$}

${ }^{1}$ Núcleo de Estudos e Pesquisas em Políticas de Segurança Pública (Neps-UFPE) e Instituto de Pesquisa em Direito e Tecnologia do Recife (IP.rec), Recife, PE, Brasil. Email: pedrosu@gmail.com ORCID: https://orcid.org/0000-0002-3806-3117.

Recebido em: 29/04/2020 | Aceito em: 16/08/2020. 


\section{RESUMO}

Partindo da problemática da ordem social e da relação entre coerção física e normas sociais, este artigo investiga as greves policiais ocorridas em Córdoba (Argentina), em dezembro 2013, e em Recife (Brasil), em maio de 2014. A partir da deflagração dessas greves, saques passaram a ser realizados por uma grande quantidade de pessoas em vários locais dos centros urbanos metropolitanos. Em meio ao medo e ao pânico, rapidamente foram suspensas atividades da vida cotidiana, enquanto indivíduos e coletivos civis organizavam modos de defesa. O que possibilitaria tão rápida disrupção da ordem social? Comparativamente, é possível observar mais semelhanças que diferenças entre os casos. Principalmente, a fundamentação constitutiva de uma ordem social assimétrica em sua coerção e o papel da rápida disseminação de informações para tomada de ações.

Palavras-chave: Ordem Social; Greves Policiais; Saques.

\section{RESUMEN}

En este artículo, se investigan las huelgas policiales que tuvieron lugar en Córdoba, Argentina, en diciembre de 2013, y en Recife, Brasil, en mayo de 2014, con base en el problema del orden social y la relación entre la coerción física y las normas sociales. Después de que estallaron las huelgas, un gran número de personas comenzó a realizar saqueos en varios lugares de los centros urbanos metropolitanos. En medio del miedo y el pánico, las actividades de la vida diaria se suspendieron rápidamente, mientras que los individuos y los colectivos organizaron defensas. La pregunta que se hace aquí es: ¿cómo es posible una interrupción tan rápida del orden social? Esta investigación encontró más similitudes que diferencias entre los casos, principalmente la base constitutiva de un orden social asimétrico en la coerción y el papel de la rápida difusión de información para tomar acciones.

Palabras Clave: Orden Social; Huelgas Policiales; Saqueos.

\section{INTRODUÇÃO}

Em 3 de dezembro de 2013, em Córdoba, Argentina, a Polícia Provincial de Córdoba (PPC) entra em greve, a qual se espalha para outras 19 províncias. No mesmo dia, saques já são registrados, barricadas são montadas e 'suspeitos' atacados. Após uso de forças militares federais para reestabelecer a ordem pública, acaba a greve de 30 horas. Cerca de seis meses depois, na noite de 13 de maio de 2014, a Polícia Militar de 
Pernambuco (PMPE), Brasil, decreta greve. Em menos de 24 horas, saques se espalham pela região da capital. Forças militares foram usadas, enquanto atividades de toda sorte foram suspensas, esvaziando ruas numa experiência singular de medo e anormalidade. As rápidas disrupções da ordem social revelam aspectos críticos.

O objetivo deste artigo é investigar processos de disrupção da ordem a partir dos casos supracitados de greve de forças policiais seguidas por saques coletivos, focalizando a relação entre polícia e dinâmicas criminais nesses períodos de enfraquecimento da capacidade estatal de reivindicar o monopólio da violência e de enforcement das leis. Como estudo exploratório, a estratégia de pesquisa envolve a investigação das duas greves, buscando identificar elementos comuns e divergentes na construção e desconstrução da ordem social. A metodologia consistiu em uma pesquisa documental a partir de fontes oficiais e jornalísticas a fim de levantar dados e informações sobre os fatos e eventos investigados. No caso cordovês, foram pesquisados os jornais Clarín, La Voz e Día a Día entre os dias 1 e 10 de dezembro. No caso pernambucano, foram pesquisados o Jornal do Commercio, G1.com e NETV entre os dias 10 a 31 de maio. Foi empregada a análise de conteúdo visando identificar fatos e eventos ocorridos, assim como elementos que permitam sua interpretação (Bardin, 2004; Bauer, 2008).

O artigo subdivide-se em sete tópicos, além dos comentários finais. Nos três primeiros tópicos busco organizar um modelo analítico para investigar essas situações a partir da problemática da ordem social, o papel da polícia na construção e manutenção da ordem social e os saques como forma de ação coletiva criminalizada. Para isso, o referencial teórico empregado parte da revisão teórica realizada por Dennis Wrong (1994) sobre o problema da ordem social dentro da sociologia, da abordagem desse problema pelo individualismo metodológico, e da escolha racional de Jon Elster (1989), passando pela discussão de Barrigton Moore Jr. (1978) sobre revolta popular, e, finalmente, pela obra “O que faz a polícia” de Dominique Monjardet (2002).

Em seguida, os dois casos sob investigação são apresentados empregando uma contextualização socioeconômica e criminal, assim como uma cronologia das greves e da criminalidade violenta ocorrida nesses períodos, construída a partir de dados estatais 
e fontes jornalísticas. Nos últimos tópicos apresento os principais achados. Primeiro aponto como as instabilidades percebidas afetaram os mais diversos atores que interpretaram, avaliaram e agiram diferentemente no 'estado de exceção', seja tomando a situação como oportunidade para ganho material, realizando uma ação coletiva e oportunista (Elster, 1994), como são os saques, cujo sucesso dependeu de mecanismos de adesão, ou seja no afastamento e entrincheiramento social motivado pelo medo dos crimes violentos que se espalharam pelas cidades, produzindo um estado latente da sociedade (Wrong, 1994).

Nos últimos dois tópicos delineio como as normas sociais e a coerção, tanto dos pares, quanto estatal, operam em diferentes níveis para o reestabelecimento da normalidade e da forma de participação nas interações cotidianas que constitui a ordem social, o que não anula, contudo, a integração dos saques ao repertório de ação coletiva que pode ser ativado em outras ocasiões, como já ocorre, em maior medida, na Argentina. Essa integração implica numa normalização dos saques, ou seja, a redução de seu caráter disruptivo da ordem social, na medida em que passam a constituir as expectativas sociais em situações de exceção como as são as greves policiais.

\section{AS (IM)POSSIBILIDADES DA ORDEM SOCIAL}

As mudanças na criminalidade durante as greves policiais de Córdoba e Recife evidenciaram que determinado nível percebido de conflito violento motivou a suspensão da vida cotidiana e rompeu com as expectativas da 'normalidade'. O conflito é central para a possibilidade de (des)ordem social e, segundo Wrong (1994), tal possibilidade envolve uma duplicidade: um nível de conflito violento considerado aceitável e sua regularidade observável que permite a previsibilidade e planejamento das rotinas. A regulação da violência é alcançada principalmente pelo uso da coerção física e da normatividade, mas interesses e desejos desempenham papéis importantes na conformação às expectativas e em sua produção.

Conflitos isolados são insuficientes para ruptura das rotinas cotidianas de uma cidade. Isso requer mudança numa escala capaz de ameaçar as redes de interdependência das sociedades modernas. Por envolverem muitas pessoas e uma impactante quebra de expectativas e rejeição pública da ordem normativa, os saques 
durante as greves policiais conseguiram a disrupção das rotinas nesses casos.

A busca por bens materiais, mas também por respeito e afeto pelos pares, por distinção, reconhecimento etc. são relevantes para a construção da ordem social, pois motivam o estabelecimento ou ruptura de relações sociais (Moore, 1978). Essa dimensão afetiva e cognitiva da ordem social implica que os indivíduos, buscando seus interesses, não são nem sempre, nem necessariamente, tampouco apenas racionais (Wrong, 1994). A aceitação de normas e de uma ordem social ocorre através das crenças dotadas de carga emocional coletivamente compartilhadas (Srbljinović \& Božić, 2014). Suas rupturas e rejeições produzem emoções que organizam as experiências.

Wrong (1994, p. 44) argumenta que a sociedade é menos uma entidade substancial e mais "um processo ou um flutuante conjunto de eventos desigualmente distribuído no espaço e tempo" que, quando não está ativada, está à disposição ou em forma latente. É uma rede de relações tecidas pelas interações e pelas expectativas sobre essas interações, essas últimas que apesar de "mero material mental, (...) prende como correntes de aço, frequentemente com poder e força igual a das leis da natureza" (Wrong, 1994, p.45). A ordem social é a distribuição desigual variavelmente organizada e consensual de interações no tempo e no espaço, dotadas de expectativas, variavelmente formalizadas e explicitadas, e baseada em relações assimétricas.

A aceitação de situações marcadas por desigualdades e desvantagens percebidas não é sempre voluntária, sendo a coerção uma das soluções para o problema de ordem social, identificada desde o clássico "Leviatã" de Thomas Hobbes. Os Estados tutelam a governança da ordem social nas sociedades modernas através da coerção como recurso de produção de regularidade e estabilidade (Elster, 1989), com possibilidades variáveis de negociação e articulação. Quanto mais imposição for aplicada, logicamente, menos consensual é o arranjo social (Moore, 1978). Durante greves policiais, o monopólio da força é precarizado e cresce a incerteza sobre o cotidiano, pois uma parte constitutiva está em falta. A questão seguinte é quão constitutiva é a parte que falta.

\section{PMPE E PPC: FORÇAS DA ORDEM?}

Para entender as reações às greves policiais, é necessário tecer alguns comentários breves e incompletos sobre essas forças públicas. Encontram-se pistas sobre o papel 
das polícias na construção da ordem social, a partir de atuação, origem, história e missão das forças policiais. Isso contribui para responder por que a ausência dessas forças públicas pode ser interpretada como oportunidade para ações criminosas por diversos atores organizados e para a incerteza e o medo generalizados. Segundo Monjardet (2002), a missão institucional é central para as polícias e suas práticas, visto que a tarefa policial é pura relação: a aplicação da força. Suas práticas organizam as relações com a sociedade e podem revelar a percepção e a interpretação dessa atuação.

No artigo 144 da Constituição brasileira consta que "a segurança pública, dever do Estado, direito e responsabilidade de todos, é exercida para a preservação da ordem pública e da incolumidade das pessoas e do patrimônio", sendo a Polícia Militar responsável pela "polícia ostensiva e a preservação da ordem pública" (Brasil, 1988). O policiamento ostensivo é uma forma de dissuadir o crime através da presença policial visível, como a patrulha e a ronda policial. A Polícia Militar foi assim denominada pela constituição de 1934 e pela Lei no192, de 17 de janeiro de 1936, estruturada a partir das Brigadas Policiais. Durante a ditadura militar, as polícias militares sofrem reorganização, sendo responsáveis pelo policiamento ostensivo e pela manutenção da ordem, por dissuadir e reprimir perturbações da ordem ${ }^{2}$, e até prevenir e reprimir subversão da ordem. A PM atuava principalmente sob uma lógica "autoritária de ordem pública que excluía os cidadãos de sua percepção" (Muniz, 2001a, p.183).

A missão da Polícia Provincial de Córdoba é, segundo a Lei de Segurança Pública da Província de Córdoba (N9.235) de 2005, “a manutenção da ordem e tranquilidade pública" no território da referida província, "exercendo as funções que a legislação estabeleça para resguardar a vida, os bens e os direitos da população". Diferentemente, das polícias militares brasileiras, essa força não é militar, ainda que possa ser considerada militarizada. Sua origem remonta a 1860, quando de sua organização, sob o comando do poder executivo provincial. As polícias provinciais fizeram parte continuamente do aparato repressivo na ditadura de 1966, no período peronista de 1973 a 1976 e durante a ditadura militar iniciada em 1976. O peronismo aprofundou a

\footnotetext{
${ }^{2}$ Segundo decreto no 88.777/1983, perturbação da ordem é qualquer ação que dificulte "o cumprimento das leis e manutenção da ordem, ameaçando a população e propriedade públicas e privadas").
} 
legislação repressiva herdada, e submeteu as polícias provinciais ao Conselho de Defesa e ao Exército para combater a "subversão". A repressão foi agudizada pela ditadura militar instalada após o golpe de estado de março de 1976 (Águila, 2013).

A noção de ordem pública, comum às duas forças públicas, consiste em fiscalização estatal ao âmbito público. Segundo Muniz (2001b, p.26), a ordem pública no Brasil é imposta e não construída pela sociedade e as polícias brasileiras são o "instrumento de imposição da ordem vinda do Estado". Como aponta Monjardet (2002), as polícias de ordem, aquelas cuja missão é a manutenção da ordem pública, possuem uma atuação que enquadra a sociedade por fora, como um corpo externo, e impõe uma determinada organização da vida decidida pelos grupos dominantes. Waldmann (2006) argumenta que os esforços de controle estatal na América Latina provocam mais desorganização social e anomia do que organização e coordenação das expectativas.

No entanto, vale ressaltar, que a polícia provincial de Córdoba também tem como missão, expressa em lei, a proteção dos direitos dos cidadãos. Essa diferença da missão em relação a PM brasileira apontaria um caráter mais híbrido da polícia provincial como força que age sobre a sociedade, mas também para a sociedade (Monjardet, 2002). Com a redemocratização, ambas as instituições passam a operar também sob a lógica de direitos e de serviço para os cidadãos. Enquanto essa mudança é manifestada na própria legislação cordovês, no caso da PMPE permanece menos institucionalizada e formalizada. Foge ao objetivo aqui avaliar o padrão de atuação das polícias atualmente.

Essas forças policiais parecem carregar na missão institucional e em seu histórico recente a atuação de imposição da ordem social top-down, pouco consensual e democrática. Assumindo que a ordem social é substancialmente alicerçada na coerção desempenhada por essas forças policiais, é possível explorar como a ausência dessas forças pode sugerir uma percepção de anormalidade. Contudo, vale salientar, há um tensionamento nessas forças fruto da redemocratização desses países nas últimas décadas do século passado. Em seguida, busco apontar alguns elementos dos saques coletivos e sua articulação com as greves policiais.

\section{SAQUES, CRIME E AÇÃO COLETIVA}

Segundo Sherman (2002), uma das grandes hipóteses sobre polícia e crime é que 
haver mais policiais nas ruas produz menos crime e se baseia nas evidências sobre greves policiais. O efeito desse 'experimento natural' é o disparo instantâneo das taxas de crime, apesar dos problemas metodológicos, excedendo qualquer variação cotidiana. A conclusão é que "o enorme tamanho dos efeitos sugere que abolir a força policial pode levar o crime a aumentar" (Sherman, 2002, p.302). Os saques ocupam um lugar excepcional aqui.

Qualquer saque articula fatores agravantes e mitigadores: a natureza da necessidade do saqueador, a natureza e quantidade de objetos saqueados, histórico criminal dos saqueadores, relação com a polícia, vulnerabilidade da vítima, grau de violência e dano causado e o fato dos saques comumente acompanharem protestos, revoltas por comida e transições políticas (Green, 2006). Green (idem) argumenta que saques são constituídos por: i) a invasão; ii) alguma forma de crime contra o patrimônio num contexto de emergência/exceção; iii) o caráter coletivo, mais comum durante distúrbios civis e raramente coordenados, e; iv) ocorrência em situações de emergência ou exceção, sem garantia de segurança, podendo ser uma estratégia de sobrevivência. O saque que provoca reações emocionais negativas intensas e são vistos como piores que roubos comuns: é o oportunista, sem ser por 'necessidade', sendo uma ação 'egoísta' num momento que demanda solidariedade, provocando "medo e ressentimento naqueles que são expostos a ele", expondo a "fragilidade de nosso contrato social" (Green, 2006, p.20).

Os períodos de greves policiais podem ser compreendidos como períodos de exceção. Uma parte constitutiva da ordem social está em falta. Nas interações cotidianas e nas expectativas sobre essas interações, que constitui o processo que é a sociedade, essa parte é um recurso/ameaça presente nas mentes ou um elemento presente de fato. Em seguida, apresentado os contextos socioeconômicos e criminais dos locais onde ocorrem as greves policiais permeadas por saques e suas cronologias, começando pelo caso de Córdoba.

\section{GREVE DA POLÍCIA PROVINCIAL DE CÓRDOBA DE 2013}

Segundo o censo argentino de 2010, a província de Córdoba possui 3.308.876 habitantes, cuja capital concentra 1.329 .604 pessoas, $40,18 \%$ da população provincial. A 
região metropolitana da Gran Córdoba possui 1.468 .842 habitantes. A densidade populacional da capital é 2308,3 habitantes por $\mathrm{km}^{3}$, valor 155 vezes maior que o valor da província. A população da Cidade de Córdoba era composta por 23,6\% de 0 a 14 anos, $26,8 \%$ de 15 a 29, por $39,4 \%$ de adultos entre 30 a 64 anos e 10,2\% de idosos acima de 65 anos. Segundo o Departamento Administrativo Nacional de Estatística (DANE), o índice de Gini da província de Córdoba registrou um decréscimo de 0,015 entre 2012 e 2013, respectivamente, de 0,542 e 0,527. O IDH da província é, para 2006 e 2011, de respectivamente, 0,824 e 0.862. Observa-se que no quarto trimestre de 2013, a taxa de emprego é a maior do ano. A taxa de indigência cresce, mas a pobreza diminui em 2013.

\begin{tabular}{|l|c|c|c|}
\hline \multicolumn{5}{|c|}{ Taxa de emprego $^{3}$} & \multicolumn{1}{c|}{ Taxa de Pessoas: Indigência e Pobreza } \\
\hline Trimestre/Ano & Gran Córdoba & Semestre/Ano & Gran Córdoba \\
\hline 4 Trim. 2010 & 42,1 & 1 Sem. 2010 & 3,$4 ; 10,0$ \\
\hline 4 Trim. 2011 & 42,8 & 2 Sem. 2010 & 1,$6 ; 7,7$ \\
\hline 4 Trim. 2012 & 44,6 & 1 Sem. 2011 & 1,$3 ; 6,1$ \\
\hline 1 Trim. 2013 & 40,7 & 2 Sem. 2011 & 1,$7 ; 6,3$ \\
\hline 2 Trim. 2013 & 42,1 & 1 Sem. 2012 & 1,$3 ; 4,9$ \\
\hline 3 Trim. 2013 & 44,2 & 2 Sem. 2012 & 0,$7 ; 5,2$ \\
\hline 4 Trim. 2013 & 44,8 & 1 Sem. 2013 & 1,$3 ; 4,9$ \\
\hline 4 Trim. 2014 & 42,9 & 2 Sem. 2013 & Não disponível \\
\hline Fonte: Instituto Nacional de Estadística y Censos de la República Argentina (INDEC) & \\
\hline
\end{tabular}

Havia um contexto de inflação na Argentina, cuja aferição pelo Indec é alvo de controvérsias desde 2007. Segundo o La Nación, enquanto o Indec apontara uma inflação de 10,3\%, em 2013, consultorias privadas a estimavam em $28,3 \%$ e, segundo PriceStats, fora $23,8 \%{ }^{4}$. Deve se considerar ainda os efeitos da crise global de 2008 , iniciada nos Estados Unidos da América e na Europa, cujos efeitos são intensos nos países periféricos. Na Argentina, a partir de 2003 são observadas taxas elevadas de crescimento, interrompidas em 2009 pela desaceleração da economia devido à crise global. Entre 2010 e 2013, o crescimento é recuperado, mas em taxas mais baixas. Segundo estudos e jornais, as populações de regiões precarizadas foram as principais

\footnotetext{
${ }^{3}$ Porcentagem da população ocupada em relação à população total (de 14 anos ou mais) Fonte: Situación y Evolución Social (Sintesis N4); INDEC. Esta série foi descontinuada pelo INDEC a partir do segundo semestre de 2013, retornando apenas em 2016.

${ }^{4}$ PriceStats publica seu índice de inflação para Argentina desde 2012 pela revista The Economist.
} 
envolvidas nos saques ocorridos. Apenas na capital de Córdoba, em 2013, eram 134 villas de emergencia ou assentamentos irregulares, onde habitavam cerca de 21.300 famílias. Calcula-se que nesses assentamentos vivem de 7,3\% da população da cidade. Isso corresponde aproximadamente a 97 mil pessoas (Argentina, 2013).

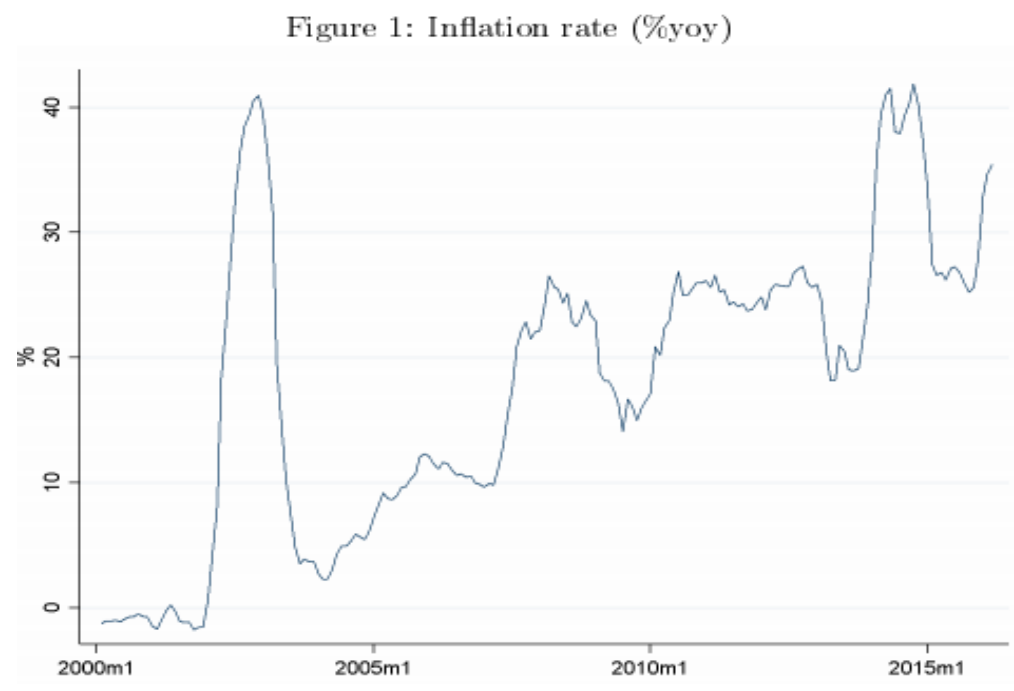

Figura 1: Taxa de inflação argentina por Cavallo e Bertolotto (2016)

Segundo estudo do Observatorio de Seguridad Ciudadana, em 2012 e 2013, o número de homicídios em Córdoba foi, respectivamente, 126 e 135. Na capital, foram 76 e 84 para esses anos, como exposto na Figura 2. A taxa de homicídios por 100 mil habitantes na província foi de 3,8 para 4,0 e, na capital, 5,8 para 6,4. Na capital, houve um aumento de 9,5\% nos homicídios, em relação a 2012. Em dezembro de 2013, mês da greve da polícia provincial, apresenta-se um valor abaixo da média do ano. Em relação ao mês de dezembro de 2012, a variação é irrelevante. Em 2014, os homicídios continuaram subindo. Na província, o total foi de 142. Desses, 86 ocorreram na capital. A taxa por cem mil habitantes na província e em sua capital foi, respectivamente, 4,29 e 6,46 . Dados de crimes patrimoniais do período entre 2009 e 2013 estavam indisponíveis para consulta, impossibilitando sua análise nesse intervalo. Em 2008, ocorreram 52.008 roubos em Córdoba, cuja taxa foi de 1.557 roubos por cem mil habitantes. Em 2014, ocorreram 65.566 roubos, equivalente à taxa de 1.858 e um aumento de $19 \%$ da taxa em relação a 2008.

Segundo o estudo "Indicadores de conflictividad social (1980-2014)" (Mayoría, 2015), entre 1989 e 2014 ocorreram 3614 saques na Argentina, concentrados em três períodos. O primeiro é entre 1989 a 1990, com 676 e 95 saques, respectivamente, cobrindo a hiperinflação ao fim do governo de Alfonsín e começo do governo de Menem. O segundo é entre 2001 a 2003, com 875, 151 e 14 saques em cada ano, e marcado por uma crise social e por falta de dinheiro. O terceiro período, com maior 
frequência de saques, é nos anos de 2012 (228 saques), 2013 (1487) e 2014 (37). O ano da onda de greves policiais que atingiu o país possui o maior valor disparado da série. ${ }^{5}$ Tamanha frequência e recorrência dos saques não são observáveis no caso brasileiro.

A greve policial de 2013 começou na província de Córdoba, dia 3 de dezembro e se espalhou por outras 19 províncias. A duração das greves e a violência que as acompanharam variaram, mas Córdoba foi a província mais saqueada: mais de mil estabelecimentos, especialmente em zonas urbanas. A declaração de greve ocorreu após semanas de malsucedidas reivindicações salariais (Añez, 2014). Em Córdoba, no dia em que a greve foi declarada, já eram relatados saques a estabelecimentos comerciais, desde supermercados a lojas de diversas categorias. Teve início uma "onda de saques e roubos, os serviços de transporte público se paralisaram e os bancos, supermercados e comércios anteciparam que hoje não abririam suas portas se não tiverem garantias de segurança para seu funcionamento" (Redacción LaVoz, 2013).

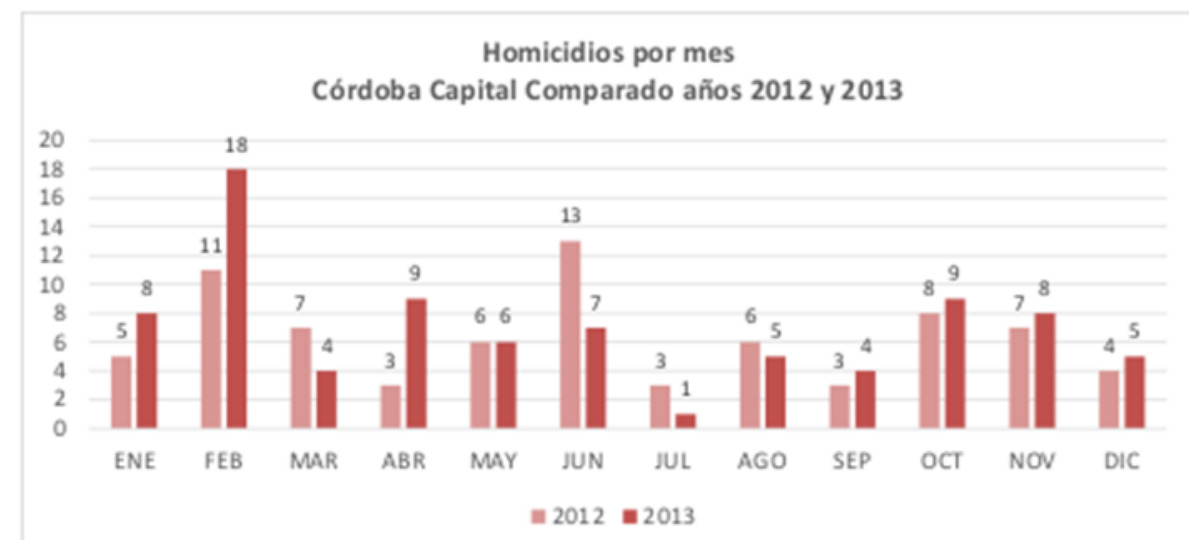

Figura 2: Homicídios por mês na capital de Córdoba, anos 2012 e 2013.

Fonte: Observatorio de Seguridad Ciudadana, 2014.

Na madrugada do dia seguinte, 4 de dezembro, comerciantes moradores de bairros de classe média organizavam defesa contra saqueadores, atacando quaisquer pessoas tidas como suspeitas (Añez, 2014). No bairro de Nova Córdoba, habitado em sua maioria por jovens e estudantes, motociclistas eram linchados (Vilarreal, 2015). A greve durou quase 30 horas e foram necessárias quatro reuniões de negociação para alcançar um acordo. A greve só encontrou seu término ao meio dia do dia 5 de dezembro, após aprovação da assembleia com 8 mil agentes policiais (Molina, 2013).

A Confederação Argentina da Empresa (Came) registrou 1900 estabelecimentos saqueados em 14 províncias e um prejuízo na casa dos 600 milhões de pesos. Estabelecimentos comerciais de alimentos, bebidas, fármacos, eletrodomésticos,

\footnotetext{
${ }^{5}$ Esses dados estão metodologicamente imprecisos, pois não há uma definição, nem detalhamentos do objeto. Não é possível, por exemplo, saber o que diferencia o saque em relação a furtos e assaltos.
} 
vestimenta, calçados, instrumentos musicais, móveis e quiosques foram afetados. Em Córdoba, segundo a Federação Comercial de Córdoba (Fedecom), o impacto ultrapassou os 313,2 milhões de pesos (Redacción Día a Día, 2013a). Mais de 200 pessoas foram detidas em Córdoba (Redacción Día a Día, 2013b). Gallino (2014) aponta a possibilidade de participação e/ou planejamento de policiais nos saques, hipótese reforçada pela prisão de policiais acusados de promoção e participação nos saques e por testemunhos de governantes que afirmaram ter sofrido "ataques de grupos organizados" (Gallino, 2014, p.261). Houve apenas um homicídio, vítima de um disparo durante um saque, e 200 feridos (Cárceres, 2013).

Hathazy (2014, p. 07) aponta que as classes altas permaneceram protegidas em suas residências, enquanto as classes média e baixa se engajaram em barricadas para se defender e que "a política de segurança parece haver adquirido (...) a centralidade (...) na conformação do sentimento particular de insegurança". Segundo Añez (2014, p. 357), os saques se constituíram como "repertório de ação coletiva arraigado nos setores populares argentinos, tendo lugar não apenas em momentos de crise econômica aguda, mas também como uma reação frente à desigualdade estrutural e à exclusão social imperantes". A internet foi uma ferramenta utilizada nesse contexto: organização de saques ou de defesa, exibição de espólios, debate, indignação, difusão de rumores, sátira e ironia aos eventos (Piccato, 2013).

Em entrevista, Paul Hathazy (Simo, 2013) observa nos protestos policiais de dezembro de 2013 uma crítica dos setores médios e baixos da polícia a seus superiores, num contexto de perda de legitimidade da polícia devido a escândalos e críticas à autoridade hierárquica e às violações dos direitos humanos. Devido à rapidez dos saques, Hathazy suspeita que a polícia pode ter aprendido a facilitá-los. Em outra entrevista, ele afirma que os eventos caóticos ocorridos revelam tensões profundas da desigualdade entre integrados à esfera do consumo e os excluídos que têm seus direitos cerceados para garantir a segurança dos outros: as políticas de segurança que segregam estão relacionadas aos saques ocorridos (Redacción LaVoz, 2013).

Svampa (2013) aponta que os saques recorrentes na Argentina são geralmente explicados pela hipótese de grande crise ou fim de época, pela conspiração de que os 
saques são organizados e planejados com antecedência, ou pela hipótese mais sociológica de que os "saques constituem um repertório de ação coletiva dos setores populares, associados a fortes estruturas de desigualdade", instalados na memória a partir de 1989. Os saques aqui se distinguem dos momentos anteriores, pois existem outros e novos atores políticos e sociais envolvidos e por ocorrerem durante a greve policial. Os saques, integrandos ao repertório de ação coletiva, abrem um intervalo temporal ou janela de oportunidade "onde toda inversão da ordem é possível" (Svampa, 2013).

Os saques expressariam o aprofundamento da fragmentação social e espacial, e seriam uma "resposta antipolítica" de inversão das assimetrias, pela tomada de bens primários e de consumo prometidos "a seus cidadãos consumidores", mas inacessíveis aos pobres, numa "rebeldia insolidária e destrutiva" que, a cada repetição, recebe novos sentidos (Svampa, 2013 s/n). Essa inflexão revela a possibilidade de guerra social marcada por forte assimetrias, pela ausência de disputas ideológicas ou políticas e pelo envolvimento de "emoções e sentimentos primários". Os saques, fundamentados em um contexto de desigualdades e insegurança urbana, se tornam um recurso político para os agentes da força pública que podem abrir a "caixa de Pandora" para reconfigurar o cenário, ao custo de potencializar preconceitos e punitivismos (Svampa, 2013).

\section{GREVE DA PMPE 2014}

Recife é a capital de Pernambuco, Brasil. A Região Metropolitana do Recife (RMR) contempla 14 municípios e tem extensão de 2773,76km². Sua população, em 2000 e 2010, era, respectivamente, de 3.337 .548 e 3.690 .547 habitantes. A densidade demográfica, em 2000, era de, aproximadamente, 1203,26hab/ $\mathrm{km}^{2}$, crescendo para 1330,52hab/km² em 2010. Para 2014, a estimativa da população da RMR pelo IBGE era de 3.887.267 habitantes, sendo 1.608 .488 , cerca de $41 \%$ residindo na capital. É a sexta metrópole mais rica em PIB PPC do Brasil. Sua economia se baseia principalmente em serviço e indústria, nessa ordem. Segundo estudo da DIEESE, a RMR termina 2013 com $13 \%$ de desempregados (da população economicamente ativa), com um aumento de 1\% em relação a 2012, interrompendo uma série história de queda iniciada 2003, e fecha 2014 com uma nova queda de $0,6 \%$ do desemprego. 
Segundo Atlas do Desenvolvimento Humano no Brasil 2013, seu IDH cresceu de 0,627 em 2000 para 0,734 em 2010, porém apresenta grande variação entre suas cidades. Abreu e Lima, por exemplo, apresenta IDH municipal de 0,679, enquanto o valor na capital é 0,772. Apesar do crescimento econômico - a renda per capita média aumentou 39,19\% entre 2000 e 2010 - o índice de Gini diminui ligeiramente nesse período, respectivamente, de 0,65 para 0,64. A porcentagem de pobres caiu mais fortemente: de $30,60 \%$ para $16,46 \%$. Segundo dados do IBGE, a RMR possui um total de 852.700 residentes em aglomerados subnormais. Em 2000, a população em favelas correspondia a $23,9 \%$ da população metropolitana de Recife, caindo para 23,5\% em 2010 (Mation et al, 2014).

A greve da PMPE de 2014 está inserida no mesmo contexto do pós-crise econômica mundial de 2008. O Brasil passou, na década anterior, por um momento de crescimento econômico graças ao boom de commodities exportadas, políticas sociais redistributivas, conseguindo reduzir a miséria, com crescimento do mercado interno e expansão do acesso ao ensino superior. A estrutura social do Brasil mudou: setores antes excluídos passam a ter acesso ao consumo através da redistribuição de renda e expansão do crédito. Em 2014, o Brasil começa a entrar em crise com a desaceleração da economia, crescimento do desemprego e da inflação, cenário agravado pela crise política desde 2014, o que culminou no impeachment de 2016.

Pernambuco vinha de uma série histórica de sete anos consecutivos de queda dos homicídios, entre 2007 e 2013. O ano de 2014 marca o fim desse ciclo de sucesso do Pacto Pela Paz, política de segurança pública executada nos governos de Eduardo Campos. Diferentemente dos Crimes Violentos Letais Intencionais (CVLI), os Crimes Violentos Não-Letais Contra o Patrimônio (CVP) não apresentavam uma tendência de queda, mas sim a variação entre os anos 2010 e 2014. O ano de 2014 apresenta, portanto, uma mudança nas tendências de CVLI e CVP em relação aos anos anteriores.

Enquanto os homicídios em 2014 constituem o fim da redução histórica, sem valores maiores que o início da série, os crimes contra o patrimônio 'explodem'. Na figura abaixo, é possível observar o mês dessa explosão, maio de 2014, mês da greve da PMPE, e seu lócus, a Região Metropolitana do Recife, o mesmo território dos saques 
ocorridos durante a greve da PMPE. Em Pernambuco, foram 6.662 ocorrências, sendo 4.799, 72,03\%, na Região Metropolitana do Recife. A capital concentra 2.694 ocorrências, equivalente a 40,43\% das ocorrências estaduais e 56,13\% dos casos da região metropolitana. O segundo maior valor nessa série é no mês de dezembro de 2011, 5.708 ocorrências, sendo 74,55\% na Região Metropolitana e 43,56\% somente na capital. O valor total em dezembro de 2011 corresponde a 86,76\% do valor de maio de 2014.

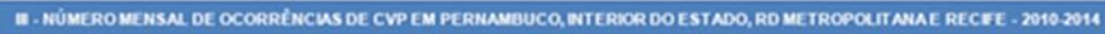

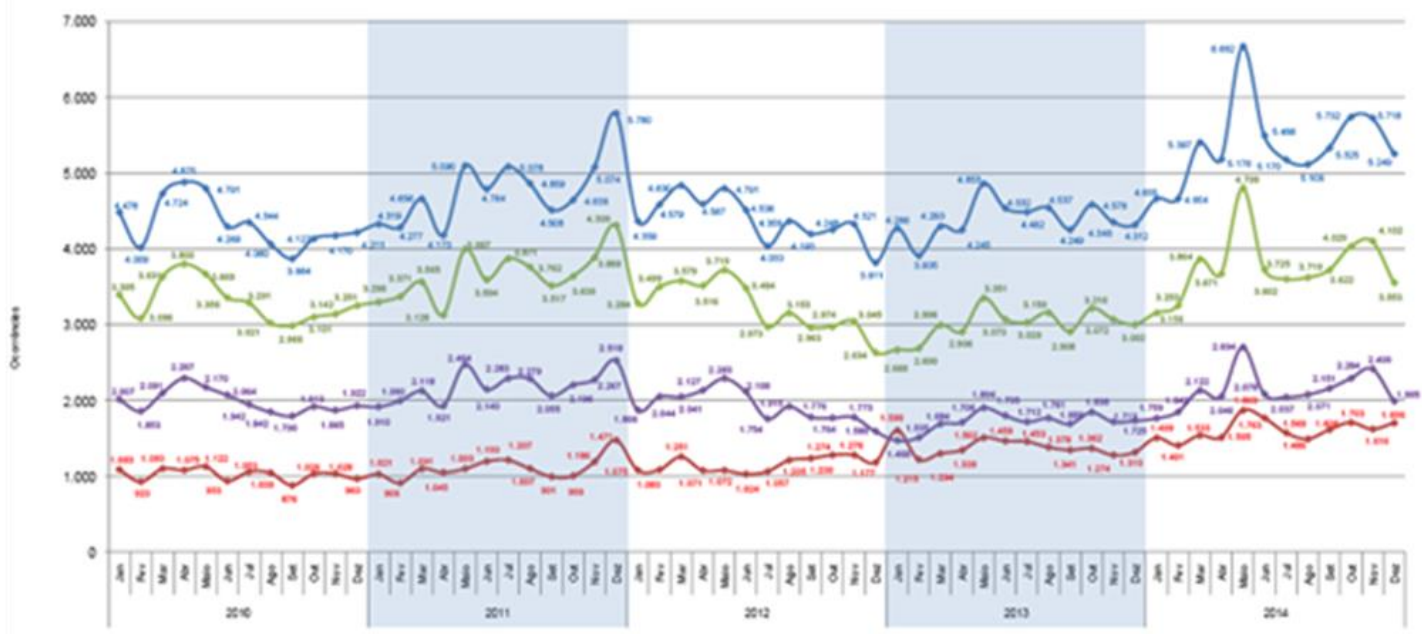

Figura 2: Número mensal de ocorrências CVP em Pernambuco, interior do Estado, Região Metropolitana e Recife - 2010-2014. Fonte: Agência CONDEPE/FIDEM.

A greve tem início na terça-feira, 13 de maio de 2014, decretada no começo da noite, após reunião com secretário da Casa Civil de Pernambuco. No fim da tarde do dia seguinte, 14 de maio, ocorrem os primeiros saques. Tiveram início na BR 101 Norte, na área que cruza o centro de Abreu e Lima, cidade periférica da RMR, e se espalharam pelo restante da cidade. Três versões, não confirmadas, sobre a origem dos saques foram encontradas: i) protesto após atropelamento de um idoso na BR que cruza Abreu e Lima, onde acidentes são recorrentes; ii) protesto contra o cancelamento das festividades do 32 aniversário da cidade; iii) estimulado por PMs.

No mesmo dia há relatos de arrastões e assaltos em várias regiões centrais e ricas da cidade do Recife, noticiados pelos jornais, mas também pelas redes sociais. Além disso, diversas universidades suspenderam as aulas noturnas. Na manhã do dia seguinte, 15 de maio, os saques passaram a ocorrer em outras regiões. Além de Abreu e 
Lima, onde supermercados foram saqueados, os atos também ocorreram em Paulista, Jaboatão dos Guararapes, Olinda e na capital, Recife, com rumores que levaram ao fechamento de diversos estabelecimentos comerciais. Durante o dia, diversos estabelecimentos e serviços foram suspensos ou sequer abriram. Além das universidades públicas e privadas com suspensão total ou parcial das atividades, o comércio de rua de shoppings, espetáculos, jogos de futebol e outros eventos foram cancelados ou adiados.

Nas redes sociais, vídeos, fotos e áudios disseminavam informações duvidosas. Vídeos e fotos viraram memes, mostrando saques a lojas, principalmente de eletrodomésticos e eletrônicos. Vestimentas, calçados e móveis foram alvos frequentes, enquanto que alimentos, produtos de higiene e bebidas foram menos comuns, evidenciando um foco em objetos de maior valor e de maior apelo de consumo. Na manhã do dia 15, quinta-feira, a Força Nacional de Segurança Pública chega a Pernambuco a pedido do então governador, a partir do decreto de Garantia de Lei e Ordem (GLO). O Exército ocupou pela tarde várias regiões da RMR. Uma operação foi montada para garantir a segurança e ordem públicas, totalizando 2240 soldados, dos quais 1300 permaneceram na RMR até dia 29 de maio. A greve termina no início da noite da dessa quinta-feira, sem atendimento da pauta de aumento salarial e desagradou uma parte dos grevistas. Na sexta-feira, dia 16, a PM voltou a operar normalmente, com o lançamento integral de 5.300 policiais militares em Pernambuco, sob o comando das Forças Armadas devido à vigência da GLO.

No mesmo dia, várias pessoas devolveram ou abandonaram os espólios dos saques. Apesar de poucas prisões, algumas pessoas se apresentaram voluntariamente ou coagidos por parentes para devolver os objetos furtados. Foram necessários pessoal e recursos extras para lidar com as devoluções e objetos abandonados. Fora divulgado que quem devolvesse não seria preso e, segundo o próprio delegado, em entrevista a um jornal local, aumentou o número de pessoas arrependidas ou com medo da punição devolvendo os bens furtados, possibilidade viabilizada pelo mecanismo jurídico de "arrependimento eficaz" (quando o efeito do crime é anulado, podendo a pena ser reduzida ou anulada). Na segunda seguinte, 19 , dois caminhões com mercadorias foram 
encaminhados para um depósito, pois lotavam a delegacia. Apenas nessa cidade, foram 25 lojas saqueadas. Uma rede varejista teve mais 500 mil reais de prejuízo em duas lojas e uma rede de supermercados registrou 700 mil reais de perdas.

Durante o período da greve, 13 a 15 de Maio, foram registrados 40 homicídios em Pernambuco, 6 a menos que os homicídios registrados no final de semana seguinte, entre 16 e 18. A média de CVLI por dia era, naquele mês e antes da greve, 9,8, valor inferior às médias de 13,3 e 15,3 para os períodos da greve e fim de semana imediatamente posterior. Em contraposição aos crimes contra o patrimônio, o crescimento dos homicídios durante a greve não configurou tamanha atipicidade. O fim de semana pós-greve registrou mais homicídios que o período da greve.

No dia 19, a Polícia Civil comunicou o saldo de 124 ocorrências de saques na RMR, sendo 37 registros nas delegacias da capital, 74 nas delegacias dos outros municípios da região metropolitana e 11 no departamento especializado. Das 102 prisões realizadas em flagrante durante a greve, 40 eram relacionadas a saques. No dia 19, cerca de 50 pessoas já haviam se apresentado e devolvido os produtos saqueados nas delegacias. A maioria dessas devoluções ocorreram em Abreu e Lima, onde vários saqueadores foram denunciados por familiares e vizinhos. Em outros focos de saques, não houve devoluções.

\section{INSTABILIDADE, INFORMAÇÃO E RUPTURA DA ORDEM SOCIAL}

A greve policial em si indica a existência de um problema institucional relevante, fundamentado em questões socioeconômicas, visto que as forças públicas, elemento fundamental dos Estados modernos (Monjardet, 2002), passam a rejeitar as ordens recebidas. A polícia, principal instrumento de reivindicação estatal do monopólio da força (Monjardet, 2002), desempenha um papel central para a legitimidade do Estado. A greve policial significa um enfraquecimento da capacidade do Estado de controlar comportamentos e, consequentemente, de coordenar as expectativas, induzir cooperação e, por fim, de produzir ordem social (Elster, 1989).

Com desentendimento endógeno, o Estado e seus agentes produzem ainda mais confusão e desordem (Waldmann, 2006), criando as condições para um estado de exceção, onde a inversão tem lugar, evidenciando a fragilidade dos contratos sociais. 
Durante as greves policiais, o custo do crime diminui: há uma janela de oportunidade para livre expressão das tensões e contradições sociais, expressas, comumente, pelo acesso violento a bens de consumo (Svampa, 2013).

Os dois casos se inserem na mesma crise econômica global. Isso aponta para a fragilização das capacidades de consumo e satisfação das necessidades (reais ou percebidas), especialmente entre os mais pobres, geralmente os primeiros a sentirem os efeitos da crise. Essas crises interromperam ciclos de crescimento e prosperidade, frustrando as expectativas e promessas de desenvolvimento econômico, de melhores condições de vida e, especialmente, de acesso à esfera de consumo.

Os saques ocorreram em cidades populosas e nas periferias, áreas de infraestrutura urbana precária, tendo as populações empobrecidas como protagonistas. Sua rápida ocorrência evidencia a instabilidade da ordem social em contexto de desigualdade e de imposição. No caso cordovês, ainda mais rápida - poucas horas se comparado ao quase um dia completo que tomou para sua realização em Pernambuco - pelo fato de saques serem um recurso integrado ao repertório de ação coletiva. Inflação, desemprego e baixos salários dificultam a satisfação das necessidades e dos desejos, reais ou produzidos, apontando falhas no arranjo social em distribuir bens e serviços. Objetos que possuem maior valor como eletrodomésticos e eletrônicos, além de necessidades básicas, foram itens saqueados. A quantidade de estabelecimentos afetados e os prejuízos produzidos alcançaram cifras milionárias.

Os saques, temporalmente localizados durante as greves, podem ser entendidos como uma forma de ação racional oportunista e egoísta, pois não é "constrangida por normas sociais" (Elster, 1994, p.79), focada no resultado, os objetos de consumo de necessidade não-básica: o saque ruim (Green, 2016). Ao mesmo tempo, ainda que muito rápido, os saques ocorreram de maneira gradual. Uma vez realizados, passaram a integrar um 'repertório de ação coletiva' (Svampa, 2013; Añez, 2014). Os saques e arrastões se caracterizam por seu caráter de ação coletiva, senão seriam apenas furtos, mais facilmente evitáveis. São ações coletivas cooperativas entre os participantes, mas competitivas em relação às vítimas. A maior adesão reduz a chance de custo (punição) e de frustração do empreendimento. 
A adesão variavelmente espontânea de grande quantidade de pessoas é explicável pelos mecanismos da norma da equidade (Elster, 1989), o apoio social e o exemplo para rejeitar a autoridade moral das normas em Moore (1978) ou o comportamento imitativo (Tarde, 1976). Segundo Elster (1989),

"A norma da equidade nos ordena seguir a maioria, seja o que ela faça. Se outros não estão cooperando, nós também não precisamos fazê-lo. (...) Práticas corruptas, por exemplo, são frequentemente defendidas pela reivindicação de que 'todo mundo faz'” (p.188-189).

O comprometimento à ordem social e a observância às normas requer visão de longo prazo e a expectativa de continuidade dessa ordem (Elster, 1989). O contexto de incerteza quanto à continuidade da ordem pode fragilizar o comprometimento com objetivos de longo prazo e os desejos imediatos podem pesar mais. O saque é oportunista, visto que a possibilidade de custo foi minimizada pela ausência de polícia, e é um meio de ganho imediato que se torna mais apelativo, enquanto os ganhos futuros do investimento na ordem social ficam mais incertos. Isso deve ser considerado num contexto de crescente dificuldade de acesso aos bens materiais através das vias legítimas e legais, dado o cenário de crise econômica.

Na medida em que os saques e as outras formas de crimes violentos ocorrem mais frequentemente e são comunicados, atuam como uma externalidade (Elster, 1994). No caso argentino, como fenômeno recorrente com variada frequência desde 1997, é uma externalidade real ou, pelo menos, possível para os atores sociais. É central, aqui, a rápida disseminação da informação e desinformação, o nexo entre ações e reações que ganha crescente importância na atualidade. A informação das greves é levada em conta na realização dos saques. Ambos, greve e saques, informam as reações de medo e de suspensão ou abandono das atividades cotidianas em larga escala. Outra reação observada em variável escala, é a defesa de si e do patrimônio, articulada através da contratação de segurança privada ou mesmo do uso de armas pelos atingidos, além da vingança contra saqueados, relatada algumas vezes sobre homicídios ocorridos na greve pernambucana. Ambas as respostas requerem algum tempo para organização.

O emprego de tropas militares nacionais para garantir a segurança, após o desentendimento institucional dentro do Estado que motiva a greve, ocorre nos dois cenários. No caso de Córdoba, o pedido de ajuda do governador da província ao 
governo nacional foi negado a princípio, somente atendido quase simultaneamente ao acordo que pôs fim à greve. O governo provincial era considerado adversário político do governo central. Tendo início em Córdoba, as greves policiais e saques se espalharam por todo o país. Posteriormente, há também um fim do ciclo político do kirschnerismo, vigente entre 2003 a 2015. No caso pernambucano, o pedido de forças é prontamente atendido, apesar de o governo estadual ter abandonado recentemente a base do governo federal. Aqui, também, observam-se crises políticas que encerram ciclos de governos. As greves e as crises, apesar de não necessariamente conectados diretamente, apontam para instabilidade institucional e perda de legitimidade estatal.

\section{NORMAS E EMOÇÕES NA CONSTRUÇÃO DA ORDEM SOCIAL}

A partir de depoimentos e entrevistas aos jornais foi possível captar algumas percepções e reações emocionais de moradores, comerciantes e transeuntes. A caracterização da situação é alarmista, empregando termos como 'caos', 'guerra civil', 'entregue aos bandidos' e às 'pessoas oportunistas'. As reações emocionais são diversas, com 'medo estampado na cara' e sentimento de 'total insegurança', 'tristeza' e 'decepção' com as pessoas da comunidade/cidade por terem participado dos saques, 'arrependimento' por ter saqueado e 'vergonha' por familiares que participaram.

A devolução, cuja ocorrência só foi encontrada na RMR, narrada em algumas entrevistas, teria sido motivada por vergonha ou por coerção familiar. A disposição de receber as sanções evidencia que a culpa e vergonha motivaram a devolução, apesar dos possíveis custos pessoais. O medo de ser preso impediria a devolução, mas motivou o abandono dos bens para evitar as sanções. Pela quantidade de objetos saqueados e pessoas envolvidas, é de se duvidar da capacidade policial de identificação dos envolvidos. A denúncia por familiares e vizinhos pode ter contribuído para as devoluções e abandonos dos espólios. No caso de Córdoba, os saques são mais 'normais', pois integrados no repertório de ação coletiva (Svampa, 2013), e a reconstrução da normalidade não incluiu devoluções e abandonos dos espólios.

Arrependimento, culpa e vergonha são emoções que dão apoio às normas sociais e que "se desencadeiam quando as normas são violadas: embaraço, culpa e vergonha no violador; raiva e indignação nos observadores" (Elster, 1994, p.137). As normas sociais 
parecem ter sido suspensas ou deixado de valer para alguns grupos e pessoas durante o período de greve, enquadrada como oportunidade de realizar desejos de consumo. Os saques foram fortes em cidades satélites do Recife, quase dormitórios, marcadas por bolsões de miséria e cujo setor mais forte é o comércio.

O caráter público dos saques é um agravante para as reações, pois, segundo Elster, "violar uma norma em público mostra um desdém pela opinião pública que é frequentemente mais severamente desaprovado que a violação da norma em si. Inversamente, escondendo a violação, o indivíduo respeita e sustenta a norma" (Elster, 1989, p.109). As emoções e as ações que motivaram ações no pós-greve desempenharam um papel de reconstrução moral da ordem social (Srbljinović \& Božić, 2014).

A suspensão das atividades foi motivada pelo medo e o pânico dos saques e outros crimes. Essa conexão é que permite o estado latente da ordem social (Wrong, 1994), quando as interações sociais são interrompidas e as pessoas se protegem nos núcleos residenciais. É válido imaginar que a expansão da esfera de consumo e suas seduções criam desejos fortes o bastante para motivar a quebra de normas por pessoas que não o fizeram anteriormente. A criação de um período de exceção pela ausência de importantes forças de imposição da ordem social é capaz de enfraquecer não apenas os custos dessas rupturas, mas a própria força normativa.

As situações analisadas são de quebra das rotinas e das expectativas que constituem a ordem social (Wrong, 1994). A devolução, o abandono ou recuperação motivada dos espólios são um esforço coletivo de retorno à normalidade. O reestabelecimento da ordem social é alcançado tanto pela reestruturação da capacidade coercitiva estatal, quanto pelo controle difuso, pelos indivíduos entre os pares e consigo mesmos.

\section{COMENTÁRIOS FINAIS}

Este trabalho tentou responder o que possibilitou tão rápida disrupção da ordem social durante as greves em questão. As respostas encontradas apontam para a fragilidade da ordem social quando fundamentada fortemente na coerção física. Essa fragilidade permanece à espreita, facilitando a disrupção quando a força se torna 
incapaz, presente também nas disputas cotidianas que tomam a forma de crimes e outros conflitos. A ausência das forças policiais nesses cenários quebra expectativas e contribui na criação de percepções e excitações capazes de mover ações como os saques ou o afastamento social. Nos casos analisados, a internet desempenhou um papel importante na disseminação de informações sobre a greve em si e sobre os saques enquanto prática possível ou ocorrida, contribuindo na produção do medo e sensação de insegurança relatados e que motivaram a fuga para os espaços privados e a interrupção das rotinas. A produção e disseminação aceleradas de informação são elementos centrais para compreender tanto as ações individuais e coletivas, quanto a própria velocidade de adesão a essas práticas que culminaram no 'estado de exceção' vivenciado. Esse tema ganha importância no momento atual de pandemia, com o que é denominado como infodemia, segundo a Organização Mundial de Saúde.

O reestabelecimento da normalidade também se organiza através das percepções, interpretações e avaliações das novidades informadas. O fim da greve e a chegada de forças militares gradualmente possibilitaram a gradual retomada da vida cotidiana. É importante, contudo, não esquecer os custos sociais possíveis de uma ordem social desigual fundamentada na imposição, como é típico na América Latina. Os custos sociais incluem a integração dos saques no repertório de ação coletiva, passando a compor o próprio horizonte de expectativas dos locais afetados. Por um lado, esforços futuros de investigação devem dar conta de sistematizar e comparar casos similares, permitindo a identificação mais consistente de padrões recorrentes. Por outro lado, argumento pela necessidade de investigações qualitativas mais aprofundadas sobre os elementos individuais e interacionais que tornam possíveis os saques nesses contextos, focalizando, especialmente, tanto as dinâmicas de iniciação e adesão dos saques, quanto as iniciativas de 'restauração da ordem' estatais e não-estatais.

\section{REFERÊNCIAS BIBLIOGRÁFICAS}

Águila, G. (2013). 'La represión en la historia reciente argentina: fases, dispositivos y dinámicas regionales'. In: Águila, G.; Alonso, L. (Coords.). Procesos represivos y actitudes sociales: entre la España franquista y las dictaduras del Cono Sur. Buenos Aires: Prometeo Libros.

Añez, P. C. S. (2014). 'Los saqueos cordobeses del 3 y 4 de diciembre de 2013 a través del humor en Internet', Question, 1(43), p. 356-371. 
Argentina, T. E. C. H. O. (2013). Relevamiento de asentamientos informales 2013. Buenos Aires.

Bardin, L. (2004). Análise de conteúdo. 3ạ. Lisboa: Edições, v. 70.

Bauer, M. W. (2008). 'Análise de Conteúdo Clássica: uma revisão'. In: M. Bauer et al., Pesquisa Qualitativa com texto, imagem e som: um manual prático, p. 189-221.

Brasil. (1988). Constituição da República Federativa do Brasil de 1988. Brasília, DF: Senado Federal. Título V, Capítulo III- Da Segurança Pública, Art. 144. Disponível em: <https://www.senado.leg.br/atividade/const/con1988 12.07.2016/art 133 asp .

[Acesso em: 28 Jun. 2019].

Cavallo, A.; Bertolotto, M. (2016). Serie Completa De Inflación De Argentina Desde 1943 a 2016 (Filling the Gap in Argentina's Inflation Data). Disponível em: < https://papers.ssrn.com/sol3/papers.cfm?abstract id=2787276>. [Acesso em: 04 de Nov. 2016].

Elster, J. (1989). The cement of society: A survey of social order. Cambridge University Press.

(1994). Peças e engrenagens das ciências sociais. Relume Dumará.

Gallino, G. E. (2014). 'Dimensiones estructurales y dinámicas de la protesta policial de diciembre de 2013: una mirada desde los medios de comunicación', Question, 1(44), p. 254-267.

Green, S. P. (2006). 'Looting, law, and lawlessness', Tul. L. Rev., v. 81, p. 11-29.

Hathazy, Paul. (2014). 'De la "seguridad ciudadana" a la "seguridad pública" en democracia: Juristas, políticos y policías en la construcción de las políticas de seguridad en Córdoba', Cuestiones de sociología, n. 10.

Mation, L. F.; Nadalin, V. G.; Krause, C. (2014). 'Favelização no Brasil entre 2000 e 2010: resultados de uma classificação comparável', Texto para Discussão 2009 (IPEA).

Mayoría, Nueva. (2015). Indicadores de conflictividad social (1980-2014). Buenos Aires: Centro de Estudios para la Nueva Mayoría. Disponível em: $<$ http://nuevamayoria.com/images/stories/celaforum/lab1501.pdf $>$. [Acesso em: 24 Nov. 2016].

Molina, G. (2013). 'El paro policial dejó el saldo de un muerto, robos y saqueos'. Clarín, 5 de dezembro. Disponível em: <https://www.clarin.com/sociedad/policial-saldomuerto-robos-saqueos 0 r1d7EKbov7g.html>. [Acesso em: 27 Out. 2016].

Monjardet, Dominique. (2002). O que faz a polícia: Uma sociologia da força pública. Ed. Rev. São Paulo: Editora da Universidade de São Paulo.

Moore, B. (1978). Injustice: The social bases of obedience and revolt. White Plains, NY: ME Sharpe. 
Muniz, J. (2001a). 'A Crise de Identidade das Polícia Militares Brasileiras', Security and Defense Study Reviews, v.1, p.187-198.

(2001b) 'Polícia brasileira tem história de repressão social', Com Ciência, Rev. eletrônica de jornalismo científico, n. 26.

Piccato, F. (2013) 'Las redes sociales jugaron un rol clave y polémico'. La Voz, 5 de dezembro. Disponível em: <https://www.lavoz.com.ar/politica/las-redes-socialesjugaron-un-rol-clave-y-polemico>. [Acesso em: 27 Out. 2016].

Redacción Día A Día. (2013a). 'Por los saqueos, \$560 millones en pérdidas', 11 de dezembro. Disponível em: <http://www.diaadia.com.ar/argentina/saqueos-560millones-perdidas $>$. [Acesso em: 27 Out. 2016].

(2013b). '200 detenidos por los saqueos', 11 de dezembro. Disponível em: <http://www.diaadia.com.ar/cordoba/200-detenidos-robos-saqueos-cordoba >. [Acesso em: 27 Out. 2016]

Redacción LaVoz. (2013). 'Indefensión: El acuartelamiento de policías derivó en una ola de inseguridad'. La Voz, Córdoba, Argentina, 5 de dezembro. Disponível em: < https://www.lavoz.com.ar/politica/indefensionel-acuartelamiento-de-policias-derivoen-una-ola-de-inseguridad-0 >. [Acesso em: 27 Out. 2016].

Simo, J. C. (2013). "'Hay una enorme deslegitimación de la Policía"'. La Voz, 15 de dezembro. Disponível em: <https://www.lavoz.com.ar/politica/hay-una-enormedeslegitimacion-de-la-policia>. [Acesso em: 27 Out. 2016].

Sherman, L. W.; Eck, J. E. (2002). 'Policing for crime prevention', Evidence-based crime prevention, v. 295.

Srbljinović, A.; Božić, J. (2014). 'Implications of the Sociology of Emotions for the Restoration of Social Order', Emotion Review, v. 6, n. 2, p. 152-159.

Svampa, M. (2013). 'La caja de Pandora de los saqueos'. Revista de Cultura Ñ, 13 de dezembro. Disponível em: <https://www.clarin.com/politica-y-economia/saqueosmaristella-svampa 0 rkYdOV-jv7x.html>. [Acesso em: 27 Out. 2016].

Tarde, G. (1976). As leis da imitação. Porto: Rés.

Villarreal, Agustin. (2015). 'Una muerte en la comisaría: reflexiones en torno a las prácticas policiales en Córdoba'. In: XI Jornadas de Sociología. Facultad de Ciencias Sociales, Universidad de Buenos Aires.

Waldmann, P. (2006). El Estado anómico. Derecho, seguridad pública y vida cotidiana en América Latina. Iberoamericana Editorial Vervuert, S.L., 2a edición revisada.

Wrong, D. (1994). Problem of Order. Simon and Schuster. 